\title{
DUAS EPIDEMIAS DE TUBERCULOSE EM CRIANÇAS MENORES DE TRÊS ANOS DE IDADE, VACINADAS COM BCG ORAL, NUMA CRECHE DO MUNICAPIO DE SÃO PAULO, BRASIL
}

Brólio, R. - Duas epidemias de tuberculose em crianças menores de três anos de idade, vacinadas com BCG oral, numa creche do município de São Paulo. Brasil. Rev. Saúde públ., S. Paulo, 8:283-96, 1974.

RESUMo: São descritas duas epidemias de tuberculose em crianças menores de 3 anos de idade vacinadas com BCG oral, ocorridas numa creche para crianças menores de 5 anos de idade, no municipio de $\mathbf{S} a ̃ o$ Paulo, nos anos de 1967 e 1969. Em 1967 havia no estabelecimento 96 crianças, inicialmente não reatoras ao teste tuberculinico padronizado (PPD, Rt-23, $2 U T$ ). Foram encontrados 19 reatores, sendo 12 reatores fortes (63,2\%) e 7 reatores fracos $(36,8 \%)$ $e$ imagens radiológicas indicativas de anormalidade pulmonar em 15 crianças ou $78,9 \%$ dos reatores. Em 1969 havia no estabelecimento mais 62 crianças não reatoras, que foram acompanhadas separadamente em relacão ao grupo de 1967 , embora convivessem no mesmo ambiente. Foram encontrados 36 reatores $\dot{a}$ tuberculina, sendo 29 reatores fortes $(80,5 \%)$ e 7 reatores fracos $(19,5 \%)$ e imagens radiológicas indicativas de anormalidade pulmonar em 11 criancas, ou $30,5 \%$ dos reatores. Nesse mesmo ano houve viragem tuberculínica em mais 7 crianças pertencentes ao grupo de näo reatores de 1967 , sendo 5 reatores fortes $e 2$ reatores fracos. Nas duas epidemias, as viragens tuberculinicas $e$ as alterações radiológicas pulmonares foram constatadas apenas nas criancas menores de 3 anos de idade, em sua maioria vacinadas previamente com 3 doses de $B C G$ oral, com intervalo de uma semana entre uma dose e outra. A fonte de infecção foi um operário que trabalhou no estabelecimento durante aproximadamente dois meses em 1967 e um mês em 1969, nos locais onde eram mantidas as crianças menores de 3 anos de idade. A vacina administrada por esse método não parece ter influenciado nas conversões tuberculinicas e no desenvolvimento de imunidade específica.

Unitermos: Infecção tuberculosa*; Epidemias (S. Paulo, Brasil)*; Crianças *; Vacinação $B C G$.

O presente trabalho tem por fim realizar o estudo retrospectivo de duas epidemias de tuberculose em crianças menores de 3 anos de idade, vacinadas com BCG oral, ocorridas numa creche no mu- nicípio de São Paulo, respectivamente nos anos de 1967 e 1969.

0 conhecimento de epidemias de tuberculose em crianças e adolescentes apresenta grande interesse sanitário e tem

* Da Disciplina de Tisiologia da Faculdade de Saúde Pública da USP - Av. Dr. Arnaldo, 715. São Paulo, SP - Brasil 
BROLIO, R. - Duas epidemias de tuberculose em crianças menores de três anos de idade, vacinadas com BCG oral, numa creche do município de São Paulo, Brasil. Rev. Saúde públ., S. Paulo, 8:283-96, 1974.

despertado a atenção dos pesquisadores, havendo freqüentemente a oportunidade de relacioná-las com a vacinação prévia pelo BCG.

Bevan et al. 2 relataram uma epidemia de tuberculose em crianças de 5 a 14 anos de idade, numa escola no município de Glamorgan, na Inglaterra, nos anos de 1942 a 1943. Num estabelecimento onde havia 186 alunos matriculados, 12 adoeceram de tuberculose. 0 foco de infecção foi um professor que esteve entre os alunos durante 5 dias, em substituição a um professor ausente.

HORTON et al. ' descreveram uma epidemia de tuberculose ocorrida nos anos de 1942 a 1944 numa escola da região urbana de New York, onde a fonte de infecção foi uma professora doente. No estabelecimento havia 203 alunos de 16 a 21 anos de idade e foram diagnosticados 16 casos de tuberculose pulmonar.

HYGE ${ }^{s}$ descreveu uma epidemia de tuberculose em escolares ocorrida no ano de 1943 na Dinamarca, numa escola pública instalada num abrigo anti-aéreo. Realizou o controle sanitário das alunas vacinadas pelo $B C G$ intradérmico e das r.ão vacinadas, que estiveram em contato durante algum tempo com uma professora tuberculosa, acompanhando-as posteriormente durante 12 anos. Esse trabalho equivale a uma observação experimental, pelo cuidado que o autor teve no seguimento das crianças sujeitas ao risco de adquirirem a enfermidade. De 368 alunas mantidas na instituição, 305 estiveram expostas ao contágio, e estavam assim distribuídas: 94 analérgicas não vacinadas, 106 analérgicas vacinadas e 105 alérgicas por infecção natural, não vacinadas. Das 94 alunas analérgicas não vacinadas, 70 apresentaram viragem tuberculinica e destas, 41 tiveram tuberculose pós-primária, evolutiva. Das 106 alunas analérgicas vacinadas, apenas duas adoeceram e, das 105 alunas alérgicas em virtude de contágios anteriores, 4 adoece- ram, sendo duas com características de infecção exógena, por contágios posteriores ao da primo-infecção natural.

A tuberculose pós-primária, evolutiva, foi constatada apenas nas crianças não reatoras e não vacinadas que estiveram em contato com o foco de infecção. Nessa epidemia ficou evidenciado que a infecção natural benigna e a vacinação pelo BCG intradérmico conferem certa proteção ao risco de adoecimento por tuberculose primária e pós-primária.

Drion et al. ${ }^{6}$ descreveram 4 epidemias de tuberculose na Holanda no período de 1933 a 1966. Em 1933, duas epidemias em escolas primárias, sendo que 43 crianças foram internadas com tuberculose pulmonar. Em ambas, a fonte de infecção foi uma professora portadora de tuberculose pulmonar. Em 1963, uma epidemia entre universitários, na qual um estudante foi o responsável pelos contágios, causando 23 casos de tuberculose pulmonar e 72 viragens tuberculínicas. Em 1966, uma epidemia entre adolescentes de 13 a 16 anos, na qual houve 35 casos de tuberculose primária e 92 casos de viragem tuberculínica, causados por um professor portador de tuberculose pulmonar.

MANDE ${ }^{12}$ faz comentários sobre 25 epidemias de tuberculose registradas no Serviço de Controle Médico Escolar da França, no período de 1948 a 1956, e evidencia o valor da vacinação como meio de proteção contra a enfermidade. Durante uma epidemia em 1954, as crianças haviam sido recentemente vacinadas, e não tiveram tempo de desenvolver o substrato imunológico. Em 1955, uma outra epidemia, numa classe com 46 alunos onde 17 haviam sido vacinados pelo BCG intradérmico e 29 eram analérgicos e não vacinados. Destes, 8 se converteram em fortemente positivos ao teste de Mantoux, sendo que em 2 houve manifestações de eritema nodoso, e em 3 
BROLIO, R. - Duas epidemlas de tuberculose em crianças menores de três anos de idade, vacinadas com BCG oral, numa creche do municipio de São Paulo, Brasil. Rev. Saude públ., S. Paulo, 8:283-96, 1974.

outros, sinais evidentes de tuberculose primária. Nos vacinados não houve nenhum caso de tuberculose pulmonar.

Em todas as epidemias descritas pelo autor, a fonte de infecção está relacionada à existência do adulto tuberculoso.

KoIKE \& KINo $^{9}$ descrevem uma epidemia de tuberculose em escolares ocorrida no Japão em 1950, numa escola com 49 alunos na qual no início do ano letivo havia 3 alunos reatores e 46 não reatores. Destes, 42 se converteram em reatores. sendo que 34 apresentaram evidência radiológica de comprometimento pulmonar. Todas as crianças que adoeceram foram medicadas, sendo que duas faleceram, uma de tuberculose miliar e outra de meningite. A fonte de infecção foi uma professora portadora de tuberculose pulmonar.

Coufal \& Svandova ${ }^{\circ}$ fizeram o controle sanitário de 597 alunos de duas escolas primárias na Checoslováquia, durante o período de 1961 a 1967, nas quais foram diagnosticados 2 professores com tuberculose pulmonar. Os alunos haviam sido previamente vacinados com BCG intradérmico. Na escola A, com 449 alunos, haviam sido vacinados $93 \%$, e na escola B, com 148 alunos, $89 \%$. A vacina utilizada apresentou diferente capacidade de alergização numa e noutra escola. Observaram que a alergia tuberculinica induzida pelo BCG tem relação com os achados clínico-radiológicos, indicando que nas crianças vacinadas com BCG de capacidade fracamente alergizante houve maior risco de adoecimento por tuberculose do que naquelas cuja reação tuberculínica pós-vacinal foi maior do que 12 $\mathrm{mm}$ de diâmetro.

Mais recentemente, em 1972, houve uma epidemia de tuberculose em crianças de 3 a 9 anos de idade, descrita por $\mathbb{W}_{\text {IL- }}$ son ${ }^{15}$, no município de Prestonpans, na Inglaterra, onde 10 crianças pertencentes a uma escola com 1.100 alunos, ficaram tuberculosas. Entre os seus contatos foram encontrados 2 adultos não pertencentes ao quadro de professores ou funcioná- rios do estabelecimento, sendo que um deles foi responsabilizado pelo adoecimento das crianças. Como medida preventiva, as demais crianças da escola foram vacinadas com $B C G$ intradérmico, utilizando o "jet injector".

As epidemias de tuberculose observadas em noso meio e já analisadas pelo autor, sob outros aspectos ${ }^{3}$, revestem-se de características inéditas por serem as crianças menores de 3 anos de idade, vivendo em ambiente fechado, e por terem sido previamente vacinadas com BCG administrado por via oral.

\section{MATERIAL E METODOS}

O material humano é constituído pelas crianças e funcionários da Creche CMS. situada no bairro de Pinheiros, em São Paulo.

A Creche está instalada num edifício relativamente amplo, tendo um andar térreo para recepção, refeitórios, administração, etc., um pavimento para as crianças maiores de 3 anos no primeiro andar, e outro pavimento para os recém-nascidos e crianças menores de 3 anos no segundo andar. As Figuras 1 e 2 mostram uma vista parcial de um dormitório do segundo andar e do pátio durante os exercícios livres.

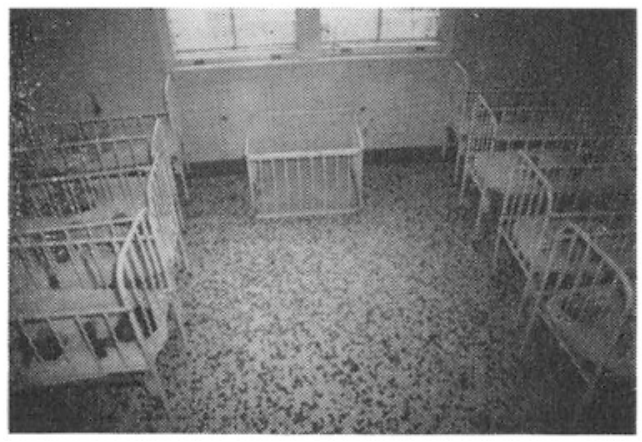

Fig. 1 - Vista parcial de um dormitório para crianças menores de 3 anos de idade, no segundo pavimento da creche CMS no municipio de São Paulo. 
BRólo, R. - Duas epidemias de tuberculose em crianças menores de três anos de idade. vacinadas com BCG oral, numa creche do municipio de são Paulo, Brasil. Rev. Saude públ., S. Paulo, 8:283-96, 1974.

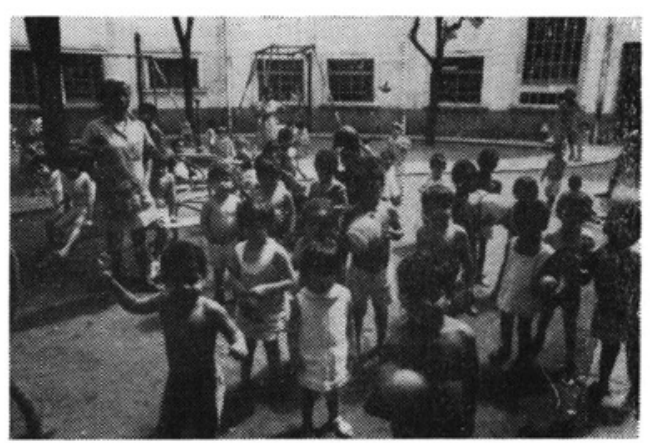

Fig. 2 - Vista parcial do pátio ocupado por criancas maiores de 3 anos de idade, durante os exercicios livres, na creche CMS no município de São Paulo.

As crianças são mantidas no estabelecimento até a idade de 5 anos, sendo posteriormente transferidas para o educandário da Instituição mantenedora da Creche, ou entregues às respectivas famílias.

0 estabelecimento está sob a orientação de uma administração leiga, particular, e conta com a assistência de pediatras, que fazem o controle da saúde das crianças e atendem os casos de emergência. A enfermagem é confiada a uma organização religiosa que dispõe também de auxiliares, geralmente egressas da própria Instituição.

As crianças são muito bem cuidadas e recebem suprimento alimentar saudável. 0 alimento básico fornecido às mesmas é o leite em pó, de boa procedência.

$A$ vacinação pelo $B C G$ era feita regularmente pela via oral, com 3 doses, sendo de $100 \mathrm{mg}$ para recém-nascidos e de $200 \mathrm{mg}$ para outras idades, com intervalo de uma semana entre uma dose e outra.

o BCG utilizado foi fornecido pelo Instituto Butantã, de São Paulo, e a vacinação obedeceu às recomendações e técnicas adotadas para a vacinação oral em nosso meio.

Os testes tuberculínicos foram feitos por aplicadoras treinadas, obedecendo à técnica recomendada pela OMS, utilizando tuberculina purificada, fornecida pela Divisão Nacional de Tuberculose, proveniente do Serum Institute de Copenhague, na dose de duas unidades (PPD, RT-23. 2 UT).

Todos os exames foram realizados no Serviço de Tisiologia do Centro de Saúde "Geraldo de Paula Souza", da Faculdade de Saúde Pública da Universidade de São Paulo.

No atendimento das crianças houve sempre o cuidado para que as mesmas não tivessem contato com os doentes normalmente atendidos no Serviço.

O exame bacteriológico não foi feito nas crianças, por apresentar rendimento muito reduzido e por não ser aplicável em programas de saúde pública para diagnóstico da tuberculose na infância, como evidencia a experiência de diferentes autores $1,4,10,11,13,14$.

0 diagnóstico da tuberculose nas crianças foi baseado no quadro tuberculínicoradiológico e nos dados epidemiológicos locais.

\section{EPIDEMIA DE 1967}

A primeira epidemia de tuberculose na Creche CMS ocorreu em julho de 1967. Havia no estabelecimento 96 crianças menores de 5 anos de idade, sendo 47 do sexo masculino e 49 do sexo feminino (Tabela 1).

$$
\text { TA B E L A } 1
$$

Distribuição, por idade e sexo, das crianças pertencentes à creche CMS, no municipio de São Paulo, no ano de 1967

\begin{tabular}{c|c|c|c}
\hline $\begin{array}{c}\text { Idade } \\
\text { em anos }\end{array}$ & $\begin{array}{c}\text { Masculi- } \\
\text { no }\end{array}$ & $\begin{array}{c}\text { Femini- } \\
\text { no }\end{array}$ & Total \\
\hline \hline $0-1$ & 6 & 10 & 16 \\
$1-2$ & 16 & 13 & 29 \\
$2-3$ & 12 & 15 & 27 \\
$3-4$ & 9 & 9 & 18 \\
$4-5$ & 4 & 2 & 6 \\
\hline Total & 47 & 49 & 96 \\
\hline
\end{tabular}


BRólio, R. - Duas epidemias de tuberculose em crianças menores de três anos de idade, vacinadas com BCG oral, numa creche do município de São Paulo, Brasil. Rev. Saude públ., S. Paulo, 8:283-96, 1974.

O levantamento tuberculínico realizado em todas as crianças do estabelecimento revelou a existência de 19 reatores, com predominância de reatores fortes $(63,2 \%$ apresentando 10 ou mais $\mathrm{mm}$ de diâmetro de reação, Tabela 2), todos pertencentes aos grupos etários com menos de 3 anos de idade e que ocupavam o segundo pavimento do edifício.
O exame radiológico dos reatores revelou a existência de sérios comprometimentos pulmonares, parenquimatosos e ganglionares em 15 crianças, conforme pode ser verificado na Tabela 3 e nas fotografias de alguns casos apresentados (Figs. 3 a 9 ).

O estudo da correlação entre os portadores de opacidades radiológicas pulmo-

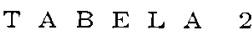

Distribuição dos reatores à tuberculina (PPD, RT-23, 2 UT) por idade, em ambos os sexos, durante uma epidemia de tuberculose na creche CMS, no municipio de São Paulo. 1967

\begin{tabular}{|c|c|c|c|c|c|c|}
\hline \multirow{3}{*}{$\begin{array}{l}\text { Idade } \\
\text { em anos }\end{array}$} & \multicolumn{6}{|c|}{ Reatores à Tuberculina } \\
\hline & \multicolumn{2}{|c|}{ Forte } & \multicolumn{2}{|c|}{ Fraco } & \multicolumn{2}{|c|}{ Total } \\
\hline & N.o & 5 & N.o & $\%$ & N.o & $c_{c}^{\prime}$ \\
\hline $0-1$ & 3 & 15.8 & 3 & 15,8 & 6 & 31,6 \\
\hline $1-2$ & 7 & 36,8 & 4 & 21,0 & 11 & 57.8 \\
\hline $2-3$ & 2 & 10,6 & - & - & 2 & 10,5 \\
\hline $3-4$ & - & - & - & - & - & - \\
\hline $4-5$ & - & 一 & - & - & - & - \\
\hline Total & 12 & 63.2 & 7 & 36,8 & 19 & 100,0 \\
\hline
\end{tabular}

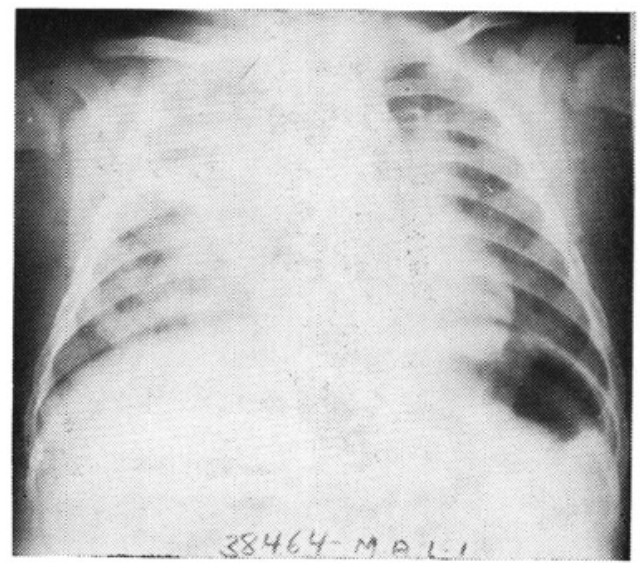

Fig. 3 - M.A.L., 1967. Alargamento do mediastino e comprometimento do parénquima pulmonar isilateral. $P P D=13 \mathrm{~mm}$.

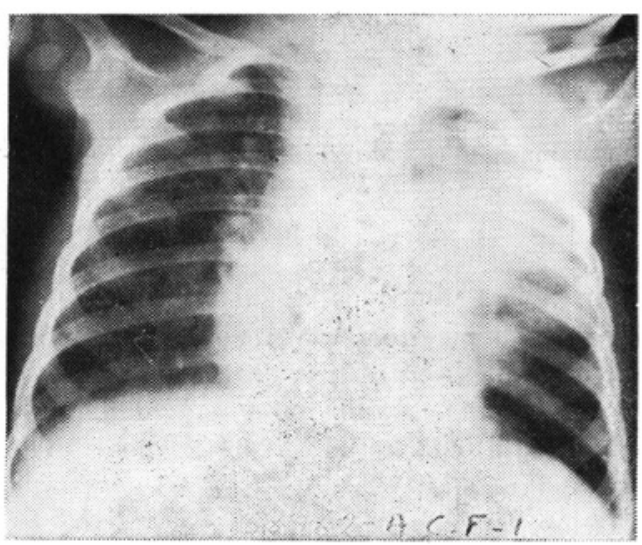

Fig. 4 - A.C.F., 1967. Alargamento do mediastino e infiltrado extenso para-hilar e campo médio $\mathrm{E}$. $\mathrm{PPD}=17 \mathrm{~mm}$. 
BRoLIO, R. - Duas epidemias de tuberculose em crianças menores de très anos de idade. vacinadas com BCG oral, numa creche do município de São Paulo, Brasil. Rev. Saúde públ., S. Paulo, 8:283-96, 1974.

\section{T A B E L A 3}

Distribuição de reatores à tuberculina (PPD, RT-23, 2 UT), e portadores de opacidades radiológicas pulmonares, por idade, em ambos os sexos, na creche CMS, no municipio de São Paulo, no ano de 1967

\begin{tabular}{c|c|c}
\hline $\begin{array}{c}\text { Idade } \\
\text { em anos }\end{array}$ & Reatores & $\begin{array}{c}\text { Opacidade } \\
\text { radiológica }\end{array}$ \\
\hline \hline $0-1$ & 6 & 5 \\
$1-2$ & 11 & 8 \\
$2-3$ & 2 & 2 \\
$3-4$ & - & -- \\
$4-5$ & - & -- \\
\hline Total & 19 & 15 \\
\hline
\end{tabular}

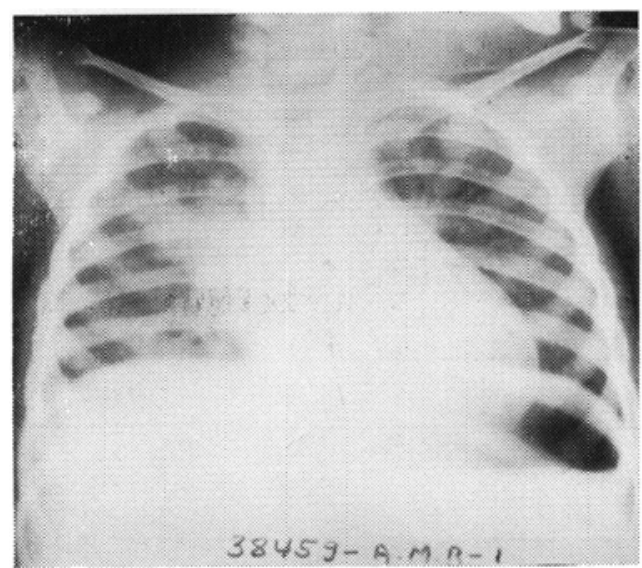

Fig. 5 - A.M.B., 1967. Alargamento do mediastino e comprometimento do parênquima pulmonar sobretudo para-hilar D. PPD = $14 \mathrm{~mm}$.

nares e a reatividade tuberculínica evidencia maior porcentagem de opacidades radiológicas entre os reatores fortes, e inversamente, maior porcentagem de pulmões sadios entre os reatores fracos ( $\mathrm{Ta}$ bela 4$)$.

Essas crianças eram inicialmente analérgicas e haviam sido vacinadas com 3 doses de BCG por via oral, com intervalo de uma semana entre uma dose e outra, havendo um período de tempo variável entre a última dose de BCG administrado e o aparecimento da epidemia (Tabela 5).

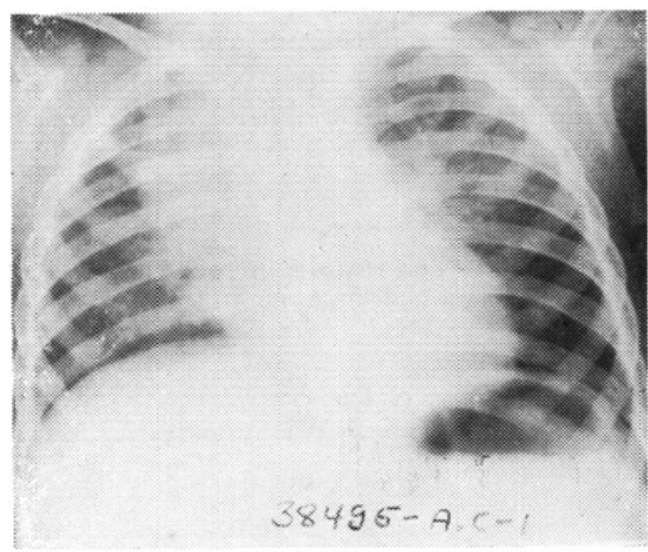

Fig. 6 - A.C., 1967, Alargamento do mediastino e comprometimento do parênquima pulmonar bilateral, sobretudo a $\mathrm{D}$. $\mathrm{PPD}=$ $5 \mathrm{~mm}$.

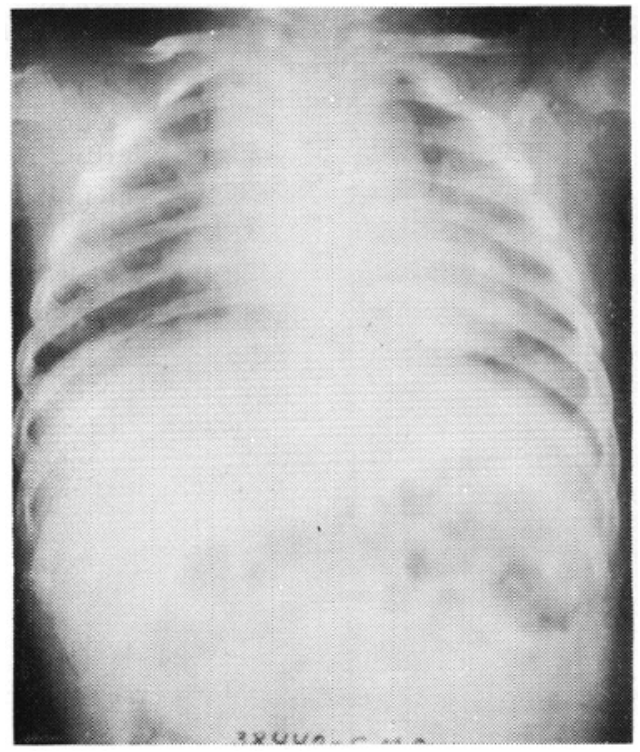

Fig. $\tau-$ C.M.S., 1967. Cadeia ganglionar para-traqueal $D$ e comprometimento do parênquima pulmonar bilateral. $\mathrm{PPD}=9 \mathrm{~mm}$. 
BROLIO, R. - Duas epidemias de tuberculose em crianças menores de tres anos de idade, vacinadas com BCG oral, numa creche do municlpio de são Paulo, Brasil. Rev. Saude públ., S. Paulo, 8:283-96, 1974.

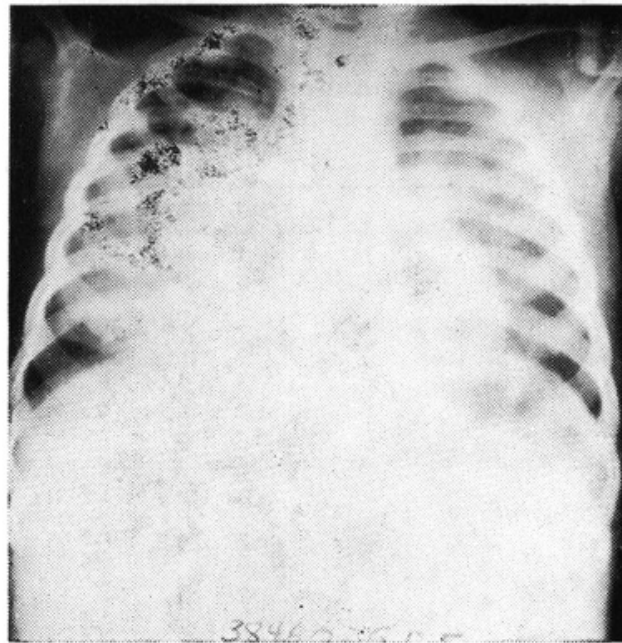

Fig. 8 - G.D.F., 1967. Adenopatla para-traqueal $D$ e infiltrado pulmonar bilateral, sobretudo à $\mathrm{D}$. PPD $=13 \mathrm{~mm}$.

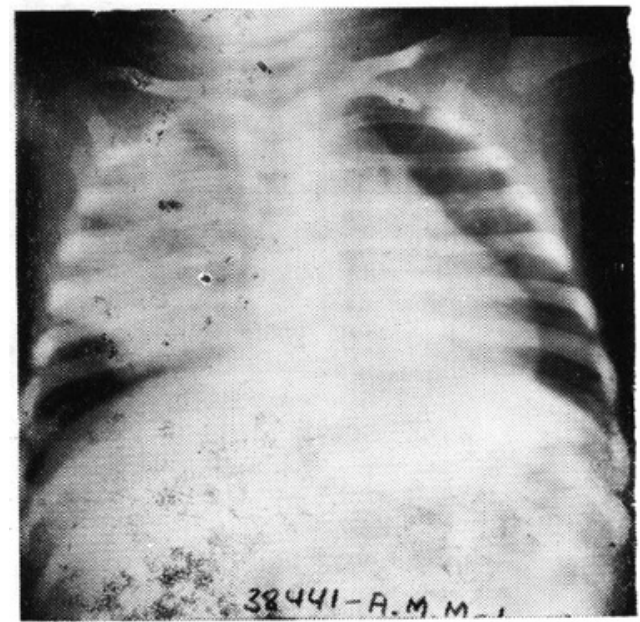

Fig. 9 - A.M.M., 1967. Alargamento do mediastino. Imagem sugestiva deatelectasia do lobo superior D. PPD $=13 \mathrm{~mm}$.

T A B E L A 4

Relação entre a intensidade da reação tuberculínica ao PPD (RT-23, 2 UT) e a presença de opacidade radiologica pulmonar, em crlanças da creche CMS, no municipio de såo Paulo, no ano de 1967

\begin{tabular}{|c|c|c|c|c|}
\hline \multirow{3}{*}{ Exame radiológico } & \multicolumn{4}{|c|}{ Reatores à Tuberculina } \\
\hline & \multicolumn{2}{|c|}{ Reator forte } & \multicolumn{2}{|c|}{ Reator fraco } \\
\hline & N.O & $\%$ & N. ${ }^{\circ}$ & $\%$ \\
\hline Opacidade radiológica & 11 & 73,4 & 4 & 26,6 \\
\hline Pulmōes sadios & 1 & 25,0 & 3 & 75,0 \\
\hline
\end{tabular}

EPIDEMIA DE 1969

A segunda epidemia de tuberculose na Creche CMS ocorreu em julho de 1969. Nessa época, o estabelecimento abrigava, além das crianças observadas no grupo de 1967, mais 62 crianças não reatoras ao serem admitidas, e que foram acom- panhadas separadamente, embora convivessem no mesmo ambiente (Tabela 6).

$O$ rastreamento tuberculínico feito nessa época revelou a existência de 36 reatores entre as crianças, com predominância de reatores fortes, todos pertencentes aos grupos etários com menos de 3 anos de idade (Tabela 7). 
BROLIO, R. - Duas epidemias de tuberculose em crianças menores de três anos de idade, vacinadas com BCG oral, numa creche do municipio de São Paulo, Brasil. Rev. Saude pübl., S. Paulo, 8:283-96, 1974.

T A B E L A $\mathbf{5}$

Distribuição das crianças vacinadas e não vacinadas com BCG oral e o tempo decorrido entre a última dose da vacina e a eclosão de um surto epidêmico de tuberculose na creche CMS no municipio de São Paulo, no ano de 1967

\begin{tabular}{|c|c|c|c|c|c|c|}
\hline \multirow{3}{*}{$\begin{array}{l}\text { Idade } \\
\text { em } \\
\text { anos }\end{array}$} & \multicolumn{4}{|c|}{ Vacinados com BCG oral } & \multicolumn{2}{|c|}{ Nāo vacinados } \\
\hline & \multicolumn{2}{|c|}{$\begin{array}{c}\text { Periodo entre a última } \\
\text { dose de BCG e a eclosão } \\
\text { da epidemia }\end{array}$} & \multirow{2}{*}{ Reator } & \multirow{2}{*}{$\begin{array}{l}\text { Não } \\
\text { Reator }\end{array}$} & \multirow{2}{*}{ Reator } & \multirow{2}{*}{$\begin{array}{l}\text { Não } \\
\text { Reator }\end{array}$} \\
\hline & $\begin{array}{c}\text { Tempo em } \\
\text { meses }\end{array}$ & N. ${ }^{\circ}$ & & & & \\
\hline $0-1$ & $\begin{array}{l}\text { - de } 2 \mathrm{~m} . \\
+ \text { de } 2 \mathrm{~m} .\end{array}$ & $\begin{array}{r}2 \\
12\end{array}$ & $\begin{array}{l}2 \\
4\end{array}$ & $\overline{8}$ & - & 2 \\
\hline $1-2$ & $\begin{array}{l}- \text { de } 2 \mathrm{~m} . \\
+ \text { de } 2 \mathrm{~m} .\end{array}$ & $\overline{25}$ & $\overrightarrow{11}$ & $\overline{14}$ & - & 4 \\
\hline $2-3$ & $\begin{array}{l}- \text { de } 2 \mathrm{~m} . \\
+ \text { de } 2 \mathrm{~m} .\end{array}$ & $\overline{25}$ & $\overline{2}$ & $\overrightarrow{23}$ & 一 & 2 \\
\hline $3-4$ & $\begin{array}{l}- \text { de } 2 \mathrm{~m} . \\
+ \text { de } 2 \mathrm{~m} .\end{array}$ & $\overline{14}$ & - & $\overline{14}$ & 一 & 4 \\
\hline $4-5$ & $\begin{array}{l}-\mathrm{de} 2 \mathrm{~m} . \\
+\mathrm{de} 2 \mathrm{~m} .\end{array}$ & $\overline{6}$ & - & - & - & - \\
\hline Total & & 84 & 19 & 65 & - & 12 \\
\hline
\end{tabular}

T A B E L A 6

Distribuição por idade e sexo de um grupo de crianças existentes na creche CMS no município de São Paulo em 1969, admitidas depois de 1968

\begin{tabular}{c|c|c|c}
\hline $\begin{array}{c}\text { Idade } \\
\text { em anos }\end{array}$ & $\begin{array}{c}\text { Masculi- } \\
\text { no }\end{array}$ & $\begin{array}{c}\text { Femini- } \\
\text { no }\end{array}$ & Total \\
\hline $0-1$ & 15 & 6 & 21 \\
$1-2$ & 14 & 11 & 25 \\
$2-3$ & 5 & 3 & 8 \\
$3-4$ & - & 3 & 3 \\
$4-5$ & 2 & 3 & 5 \\
Total & 36 & 26 & 62 \\
\hline
\end{tabular}

O exame radiológico dos reatores evidenciou a existência de 11 crianças portadoras de anormalidade pulmonar, conforme pode ser observado na Tabela 8 e nas fotografias de alguns casos apresentados (Figs. 10 e 11).

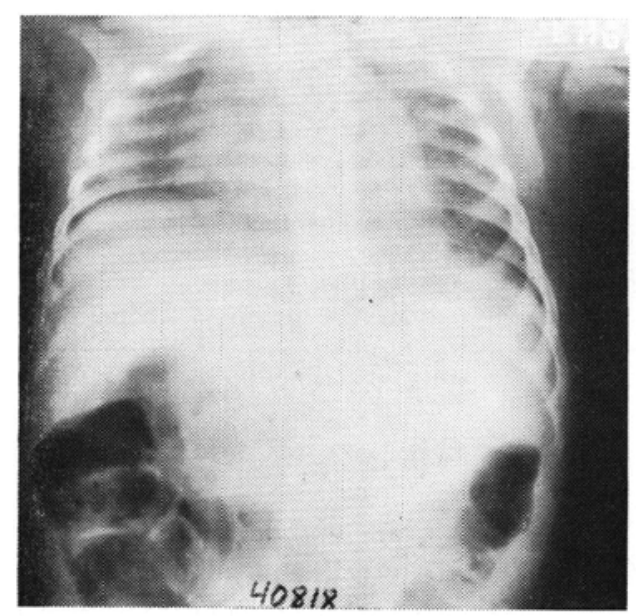

Fig. 10 - J.E.H.G., 1969. Cadela ganglionar para-traqueal bil. e infiltrado pulmonar para-hilar D. PPD $=10 \mathrm{~mm}$. 
BRólio, R. - Duas epidemias de tuberculose em crianças menores de três anos de idade, vacinadas com BCG oral, numa creche do município de são Paulo, Brasil. Rev. Saúde puibl., S. Paulo, 8:283-96, 1974.

T A B E L A 7

Distribuição dos reatores à tuberculina (PPD, RT-23, 2 UT), por idade, em ambos os sexos, durante uma epidemia de tuberculose na creche CMS, no município de São Paulo, no ano de 1969

\begin{tabular}{|c|c|c|c|c|c|c|}
\hline \multirow{3}{*}{$\begin{array}{l}\text { Idade } \\
\text { em anos }\end{array}$} & \multicolumn{6}{|c|}{ Reatores à Tuberculina } \\
\hline & \multicolumn{2}{|c|}{ Forte } & \multicolumn{2}{|c|}{ Fraco } & \multicolumn{2}{|c|}{ Total } \\
\hline & N.o & $\%$ & N.O & $\%$ & N.o & $\%$ \\
\hline $0-1$ & 15 & 41,7 & 1 & 2,8 & 16 & 44.5 \\
\hline $1-2$ & 11 & 30,5 & 4 & 11,2 & 15 & 41,7 \\
\hline $2-3$ & 3 & 8,3 & 2 & 5,5 & 5 & 13,8 \\
\hline $3-4$ & - & - & 一 & - & - & 一 \\
\hline $4-5$ & - & 一 & - & - & - & - \\
\hline Total & 29 & 80,5 & 7 & 19,5 & 36 & 100,0 \\
\hline
\end{tabular}

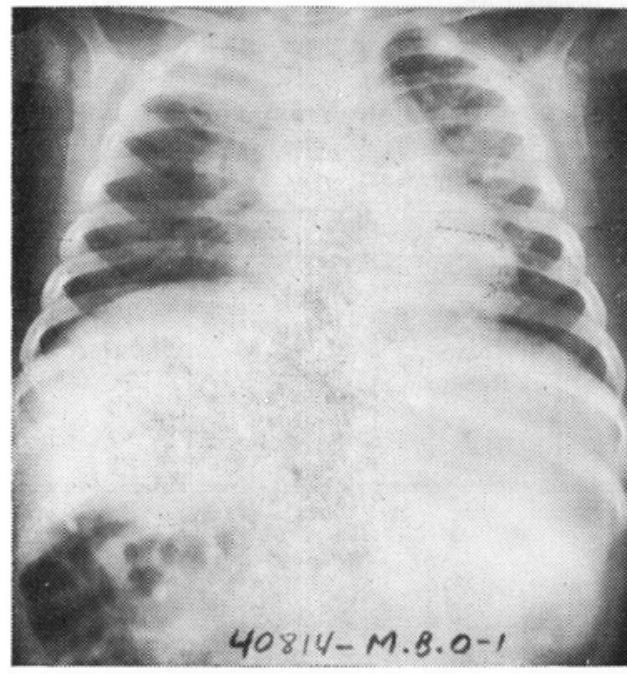

Fig. $11-$ M.B.O., 1969. Alargamento do mediastino. Infiltrado pulmonar bilateral, sobretudo à D. PPD $=17 \mathrm{~mm}$.

O estudo da correlação entre os portadores de opacidades radiológicas pulmonares e a intensidade da reação tuberculínica mostra que todos os portadores

\section{T A B E L A 8}

Distribuição dos reatores à tuberculina (PPD, RT-23, 2 UT) e portadores de opacidades radiológicas, por idade, em ambos os sexos, na creche CMS, no municipio de São Paulo, no ano de 1969

\begin{tabular}{c|c|c}
$\begin{array}{c}\text { Idade } \\
\text { em anos }\end{array}$ & Reatores & $\begin{array}{c}\text { Opacidade } \\
\text { radiológica }\end{array}$ \\
\hline \hline $0-1$ & 16 & 8 \\
$1-2$ & 15 & 3 \\
$2-3$ & 5 & - \\
$3-4$ & - & - \\
$4-5$ & - & - \\
Total & 36 & 11 \\
\hline
\end{tabular}

de opacidade radiológica são reatores fortes, enquanto os que apresentam pulmóes sadios estão distribuídos entre os reatores fracos em $28 \%$ e reatores fortes em $72 \%$ (Tabela 9). 
BRólio, R. - Duas epidemias de tuberculose em crianças menores de três anos de idade. vacinadas com BCG oral, numa creche do municipio de são Paulo, Brasil. Rer. Saúde públ., S. Paulo, 8:283-96, 1974 .

T A B E L A 9

Relação da intensidade da reasão tuberculinica ao PPD, RT-23, 2 LT e a presença de opacidade radiológica pulmonar em criancas da creche CMS, no município de São Paulo, no ano de 1969

\begin{tabular}{|c|c|c|c|c|}
\hline \multirow{3}{*}{ Exame radiológico } & \multicolumn{4}{|c|}{ Reatores à tuberculina } \\
\hline & \multicolumn{2}{|c|}{ Reator forte } & \multicolumn{2}{|c|}{ Reator fraco } \\
\hline & N.O & 50 & N.O & $S_{0}$ \\
\hline Opacidade radiológica & 11 & 100,0 & 一 & - \\
\hline Pulmões sadios & 18 & 72,0 & 7 & 28,0 \\
\hline
\end{tabular}

As crianças eram inicialmente analérgicas, e haviam sido vacinadas com 3 doses de BCG por via oral, com intervalo de uma semana entre uma dose e outra, havendo um período de tempo variável entre a última dose de BCG administrada e a eclosão da epidemia (Tabela 10).

Resta acrescentar que das 77 crianças nāo reatoras do grupo de 1967 , as que permaneceram no estabelecimento foram

\section{T A B E L A 10}

Distribuicão das crianças vacinadas com BCG oral e o tempo decorrido entre a última dose da vacina e a eclosão de um surto epidémico de tuberculose na creche CMS no município de São Paulo, no ano de 1969

\begin{tabular}{|c|c|c|c|c|c|c|}
\hline \multirow{3}{*}{$\begin{array}{l}\text { Idade } \\
\text { em } \\
\text { anos }\end{array}$} & \multicolumn{4}{|c|}{ Vacinados com BCG oral } & \multicolumn{2}{|c|}{ Nāo racinados } \\
\hline & \multicolumn{2}{|c|}{$\begin{array}{c}\text { Período entre a última } \\
\text { dose de BCG e a eclosāo } \\
\text { da epidemia }\end{array}$} & \multirow{2}{*}{ Reator } & \multirow{2}{*}{$\begin{array}{l}\text { Não } \\
\text { Reator }\end{array}$} & \multirow{2}{*}{ Reator } & \multirow{2}{*}{$\begin{array}{l}\text { Não } \\
\text { Reator }\end{array}$} \\
\hline & $\begin{array}{c}\text { Tempo } \\
\text { em meses }\end{array}$ & N.o & & & & \\
\hline $0-1$ & $\begin{array}{l}-2 \text { meses } \\
+2 \text { meses }\end{array}$ & $\begin{array}{r}12 \\
5\end{array}$ & $\begin{array}{r}11 \\
5\end{array}$ & 1 & 一 & 2 \\
\hline $1-2$ & $\begin{array}{l}-2 \text { meses } \\
+2 \text { meses }\end{array}$ & $\begin{array}{r}16 \\
3\end{array}$ & $\begin{array}{r}11 \\
1\end{array}$ & $\begin{array}{l}5 \\
2\end{array}$ & 3 & 4 \\
\hline $2-3$ & $\begin{array}{l}-2 \text { meses } \\
+2 \text { meses }\end{array}$ & $\begin{array}{l}6 \\
3\end{array}$ & $\begin{array}{l}2 \\
2\end{array}$ & $\begin{array}{l}4 \\
1\end{array}$ & 1 & - \\
\hline $3-4$ & $\begin{array}{l}-2 \text { meses } \\
+2 \text { meses }\end{array}$ & $\overline{2}$ & - & $\overline{2}$ & 一 & 1 \\
\hline $4-5$ & $\begin{array}{l}-2 \text { meses } \\
+2 \text { meses }\end{array}$ & - & 一 & $\overline{4}$ & 一 & - \\
\hline Total & & 51 & 32 & 19 & 4 & 7 \\
\hline
\end{tabular}


BRólo, R. - Duas epidemias de tuberculose em criancas menores de tres anos de idade, vacinadas com BCG oral, numa creche do município de săo Paulo, Brasil. Rev. Saúde públ., S. Paulo, 8:283-96, 1974.

acompanhadas e se mantiveram negativas ao teste tuberculínico durante $o$ ano de 1968. No ano de 1969 havia ainda 49 crianças daquele grupo, e o teste tuberculínico realizado nas mesmas revelou a existência de 7 reatores, sendo 5 reatores fortes e 2 reatores fracos, todos com pulmões sadios.

\section{CARACTERISTICAS COMUNS AS DUAS EPIDEMIAS}

Nas duas epidemias de tuberculose ocorridas na Creche CMS estão presentes os seguintes elementos:

1. eclosão simultânea, num período médio de 2 meses, em grande número de crianças;

2. viragem tuberculínica com predominância de reatores fortes;

3. presença de opacidades radiológicas pulmonares entre os reatores, sugestivas de tuberculose;

4. predominância de reatores fortes à tuberculina entre os portadores de opacidade radiológica pulmonar;

5. acometimento de crianças com menos de 3 anos de idade, que ocupavam o segundo pavimento do edifício.

\section{PESQUISA DA FONTE DE INFECCÃO}

A pesquisa do foco foi realizada em 1967 e 1969 pelo exame abreugráfico e complementação pelo exame de escarro, quando necessário, de todos os funcionários e pessoas que pudessem ter tido contato com as crianças.

Em fevereiro de 1969 constatou-se que um operário contratado esporadicamente pela Instituição desde 1966 para executar reparos e serviços gerais no edifício, era portador de tuberculose pulmonar crônica, bilateral, escavada, com baciloscopia positiva (NTA-II) (Fig. 12).

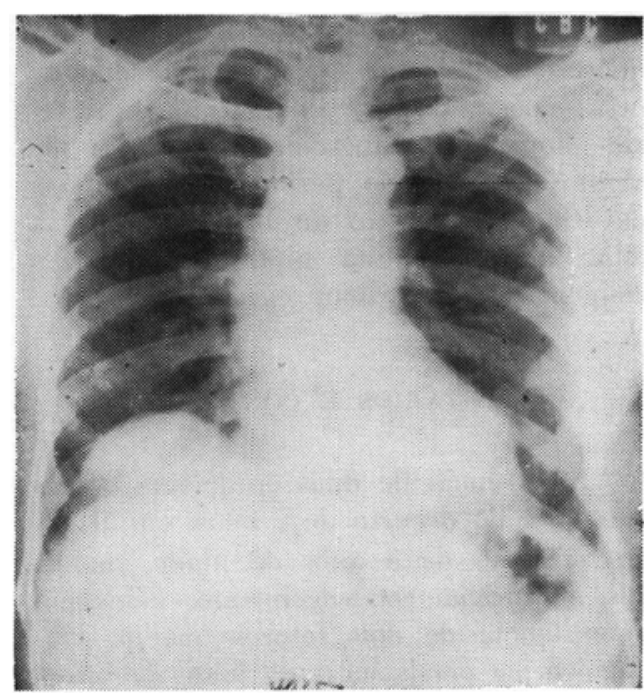

Fig. 12 - C.B.C., 1969. Tuberculose pulmonar bilateral. Cavidade infra-clavicular $E$. (N.T.A.-II) baciloscopia positiva.

Ao que se pôde apurar, o referido operário trabalhou na Creche CMS durante os meses de dezembro de 1966 a fevereiro de 1967, e posteriormente, durante o mês de janeiro e início de fevereiro de 1969. Em julho de 1967, por ocasião da primeira epidemia, ele já não trabalhava no local, e em fevereiro de 1969, quando foi encaminhado para exames, vinha trabalhando no estabelecimento há cerca de 30 dias. Nessa época, foi afastado de suas atividades e encaminhado ao Centro de Saúde da Lapa (São Paulo), por residir na área de atendimento dessa unidade sanitária.

No Centro de Saúde da Lapa (Prontuário n. $\left.{ }^{\circ} 10.768 / 69\right)$, consta que o paciente nunca havia tomado medicamentos específicos (V.T.) e tinha um irmão tuberculoso. Não quis ser internado, não voltou para tratamento no Centro de Saúde e mudou de residência, não tendo sido localizado pela visitadora domiciliar. Não se conseguiu nenhum exame do seu estado de saúde de época anterior à data em que sua doença foi diagnósticada 
BRólio, R. - Duas epidemias de tuberculose em crianças menores de três anos de idade vacinadas com BCG oral, numa creche do municipio de são Paulo, Brasil. Rev. Saúde públ., S. Paulo, 8:283-96, 1974.

(fevereiro de 1969), mas a julgar pelo quadro radiológico de sua enfermidade nessa época, pode-se deduzir que a referida forma de tuberculose já vinha de algum tempo e, no período de dezembro de 1966 a fevereiro de 1967, já deveria estar doente. Nesta hiptese, ele foi o responsável pelas duas epidemias.

\section{COMENTARIOS E CONCLUSOES}

A ocorrência de duas epidemias de tuberculose no decurso de 2 anos, em crianças menores de 3 anos de idade, mantidas no mesmo estabelecimento, evidencia a existência de dois fatores que as predispõem: a persistência da fonte de infecção e a inexistência de resistência natural e de imunidade específica em nível suficiente para proteger as crianças ao risco de adoecimento.

A gravidade da doença tuberculosa está na dependência dos gradientes que presidem o binômio do conflito biológico germe-hospedeiro, representado por um lado pela fonte de infecção, repetição de contágios, virulência e número de bacilos $\mathrm{e}$ por outro, pela proteção conferida pela resistência natural e pela imunidade de qualquer modo induzida.

Um operário contratado esporadicamente para realizar serviços diversos no edifício foi o causador da epidemia de 1969 e embora não tenhamos dados que comprovem sua relação com a epidemia de 1967, há razões científicas que justificam essa hipótese. Baseando-nos no conhecimento de sua enfermidade em 1969, pois era portador de tuberculose pulmonar escavada, com baciloscopia positiva; pelos seus antecedentes, de ter trabalhado na Creche no periodo de dezembro de 1966 a fevereiro de 1967; e pela identidade das duas epidemias, acometendo crianças menores de 3 anos de idade que ocupavam o segundo pavimento do edifício, nos locais onde ele trabalhava e andava entre os berços ocupados pelas mesmas, podemos afirmar que ele foi também responsável pela epidemia de 1967.

O comprometimento de crianças menores de 3 anos de idade, nas duas epidemias, explica-se pelo fato de as mesmas permanecerem em seus berços durante o período em que o operário ficava trabalhando, enquanto as crianças maiores eram encaminhadas aos pátios, ficando isentas do contágio (Figs. 1 e 2).

E necessário destacar que os adultos que vão trabalhar em estabelecimentos ou enfermarias de crianças devem ser prévia e periodicamente examinados. Não obstante a motivação despertada pela epidemia de 1967, aquele operário encarregado de executar pequenos serviços no prédio, foi contratado em 1969 e trabalhou cerca de um mês entre as crianças, antes de ser encaminhado para os exames de saúde.

A constatação de formas graves, clínico-radiológicas de tuberculose, em grande porcentagem de crianças previamente vacinadas nas duas epidemias, faz pensar na ausência de proteção específica conferida pelo BCG administrado. Não se pode, contudo, por esta observação, desmerecer o valor da vacina oral, pois não se contou com um grupo testemunho equivalente para comparação. Não houve, a bem da verdade, nas duas epidemias, nenhum caso de complicação meningo-encefálica ou de secundarismo, ressaltando-se ainda que em 1969, das 32 crianças reatoras que haviam tomado BCG (Tabela 10), 24 delas, ou $75 \%$ tomaram a última dose da vacina há menos de dois meses antes da eclosão da epidemia, ainda no período de incubação dos bacilos-vacina. tempo insuficiente para se ter o desenvolvimento da imunidade específica.

As conversōes tuberculínicas encontradas poderiam ser atribuídas ao BCG. Acontece, porém, que o BCG foi administrado igualmente às crianças dos diferen- 
BROLIO, R. - Duas epidemias de tuberculose em crianças menores de três anos de idade, vacinadas com BCG oral, numa creche do municipio de Sáo Paulo, Brasil. Rev. Saúde públ., S. Paulo, 8:283-96, 1974.

tes grupos etários, não se explicando a falta de reatividade nas crianças maiores de 3 anos, uma vez que foram empregados a mesma vacina e o mesmo método de administração para todas as crianças. Houve, ainda, na epidemia de 1969, a viragem tuberculínica em 4 crianças que, por algum motivo, não haviam tomado BCG (Tabela 10), sendo mais um argumento para se excluir a interferência da vacina nas conversóes tuberculínicas descritas.

Este relato evidencia a necessidade de se manter a vigilância sanitária perma- nente nos estabelecimentos que abrigam crianças. A tuberculose é uma doença transmissivel, que pode se propagar rapidamente se os meios de prevenção contra a mesma forem relegados a plano secundário.

As epidemias de tuberculose em crianças podem ser constatadas em qualquer país e representam uma advertência para os profissionais de saúde, para que tenham em mente que os métodos já consagrados de profilaxia são altamente justificáveis e devem ser aplicados com o máximo rigor.

RSPU-B/223

BRóLIo, R. - [Two epidemics of tuberculosis in children under three years of age vaccinated with oral BCG in a day-nursery in S. Paulo county, Brazil.] Rev. Saúde públ., S. Paulo, 8:283-96, 1974.

SUMMARY: Two epidemics of tuberculosis in children under three years of age vaccinated with oral BCG, in the year of 1967 and 1969, in a day-nursery in S. Paulo borough, are here described. In 1967 there were 96 children in the place, at first non-reactors, to the standard tuberculine test $(P P D, R T-23,2 U T)$. There were found 19 reactors, being 12 strong reactors (63,2\%) and 7 weak reactors $(36,8 \%)$, and in 15 children or $78,9 \%$ of the reactors, the chest $X$-Rays showed pulmonary abnormalitity. In 1969 there were 62 more children in the institution, initially non-reactors, who were followed-up separately in relation to the 1967 group, although they were in the same environment. There were found 36 reactors to tuberculine, being 29 strong reactors $(80,5 \%)$ and $\gamma$ weak reactors $(19,5 \%)$ and the chest $X$-Rays showed pulmonary abnormality in 11 children or $30,5 \%$ of the reactors. In that same year there was a tuberculine change in 7 more children, beloging to the non-reactor group of 1967, being 5 strong reactors and 2 weak ones. In both epidemics the tuberculinic changes and the alterations in the pulmonary $X$-Rays were manifested only in children under 3 years of age, the majority previously inoculated with 3 dosages of oral BCG, with one week interval between two dosages. The source of the infection was a workman who worked in the place among the children under 3 years of age, during approximately two months in 1967 and one month in 1969. The vaccine given by such $a$ method seemed not to have influenced the tuberculine conversions and the development of the specific immunity.

UNITERMS: Tuberculosis infection*; Epidemies, S. Paulo (Brazil)*; BCG vaccination*. 
BRolio, R. - Duas epidemias de tuberculose em criancas menores de três anos de idade, vacinadas com BCG oral, numa creche do municipio de são Paulo, Brasil. Rev. Saúde públ., S. Paulo, 8:283-96, 1974 .

\section{REFERENCIAS BIBLIOGRÁFICAS}

1. ALVIM, A. \& NASCIMENTO, E. A. do - Quadros pulmonares nos vacinados pelo método concorrente na "Favela da Praia do Pinto". Rev. Bras. Tuberc., 22:889-908, 1954.

2. BEVAN, R. T, et al. - An outbreak of respiratory tuberculosis in a school. Brit. med. J., 2:828-30, 1951.

3. BROLIO, R. - Controle de duas epidemias de tuberculose em crianças menores de 5 anos de idade vacinadas com BCG oral, ocorridas nos anos de 1967 e 1969, numa creche no municipio de São Paulo. São Paulo, 1972. [Tese de doutoramento - Faculdade de Saúde Pública da USP].

4. CARVAlHo, A. de - Tuberculose na criança. Rev. bras. med., 24:881-4, 1967.

5. COUFAL, K. \& SVANDOVA, E, - L'occurrence de la tuberculose epidemiologique dans les écoles chez enfants calmettises. Bull. Un. int. Tuberc., 41: 83-5, 1968.

6. DRION, R. et al. - Tuberculosis epidemics in the Netherlands. Bull. Un. int. Tuberc., 41:64- $72,1968$.

7. HORTON, R. et al. - Epidemic of tuberculosis in a high school: report of eight years follow-up of students exposed. J. Amer. med. Ass., 149: $331-4,1952$.

8. HYGE, T, V. - The efficacy of $\mathrm{BCG}$ vaccination. Epidemic of tuberculosis in a state school, with an obser- vation period of 12 years. Acta tuberc. scand., 32:89-107, 1956.

9. KOIKE, S. \& KINO, C. - Epidemic of tuberculosis in Miyota primary school of Nagano-Ken. Rep. Med. Res. Probl. Jap. Anti-tuberc. Ass,, 17:104$13,1969$.

10. LIMA FILHO, M. T. - Diagnóstico e orientação terapêutica da tuberculose infantil pelo dispensário. Rev. bras. Tuberc., 22:153-62, 1954.

11. LOTTE, A. et al. - Epidemiologie de la tuberculose et defailances de la lutte anti-tuberculeuse chez l'enfant. Bull. org. mond. Santé, 44(supl.):1-230, 1971.

12. MANDE, R. - Epidemies scolaires de tuberculose et vaccination BCG. Bull. int. Tuberc., 41:73-8, 1968.

13. PAULA, A. de \& LIMA, M. M. P. de Diagnóstico da tuberculose na infância. Rev. Serv. nac. Tuberc., 1:321$-32,1957$.

14. VASQUEZ, J. R. - Tuberculosis intratorácica en la primera infancia. Buenos Aires, Ed. Hector Macchl, 1960.

15. WILSON, H. D. - Experience of BCG vaccination by jet injection in an outbreak of primary tuberculosis. Lancet, 1:927-8, 1973 .

Recebido para publicą̧̃o em 12-6-1974 Aprovado para publicação em 9-8-1974 